Disclosure of Interest: None declared

DOI: 10.1136/annrheumdis-2017-eular.3848

\section{AB1033 THE EXPRESSION OF IMMUNOGLOBULIN G AND IMMUNOGLOBULIN G4 IN LYMPHOMA}

J. Li ${ }^{1}$, Z. Zhang ${ }^{2} .{ }^{1}$ Rheumatology department, Shanxi Dayi Hospital, Shanxi; ${ }^{2}$ Rheumatology department, Peking University First Hospital, Beijing, China

Background: Although IgG4-related disease has been gradually recognized, its relationship with malignant diseases, especially lymphoma has been an eternal topic.

Objectives: To explore the expression of lgG4 positive cells in lymphoma.

Methods: Surgical excision specimens with definite diagnosis of lymphoma from January to December, 2013 were collected. Hematoxylin-eosin staining and immunohistochemical staining of $\lg G$ and $\lg G 4$ were then evaluated on dense lymphoplasmacytic infiltration, storiform fibrosis and obliterative phlebitis. For the quantification of $\lg G$ and $\lg G 4$ positive cells, the areas with the highest density of positive cells were evaluated. Three high-powered fields (hpf) in each section were analyzed, and the average number of positive cells per hpf was calculated. Results: 16 patients with lymphoma were selected in our study. There were 9 males and 7 females with an average age of 51 years old. The pathologic type included 13 cases of non-Hodgkin lymphoma and 3 cases of Hodgkin lymphoma. Sub types of Non-Hodgkin lymphoma contained 8 cases of diffuse large B cell lymphoma, 2 cases of small B cell lymphoma, 1 case of mucosa accociated lymphoid tissue marginal zone B cell lymphoma (MALToma), follicular lymphoma, peripheral T-cell lymphoma and hepatosplenic T-cell lymphoma. The 16 specimens all manifested as dense lymphocytic infiltration, accompanied by atypical cases were IgG positive with the highest cell count from 20-350/hpf. IgG can be expressed in both cytoplasm and cytomembrane. 2 cases of IgG4 positive were Hodgkin lymphoma and the highest cell counts were 11 and $12 / \mathrm{hpf}$ respectively.

Conclusions: IgG4 positive cell, fibrosis and obliterative phlebitis seldom appear in lymphoma. Added specific tumor signature molecules, it may not be difficult to distinguish lymphoma from lgG4-related disease.

References:

[1] Stone JH, Zen Y, Deshpande V. IgG4-related disease. N Engl J Med 2012 2012-02-09;366(6):539-51.

[2] Yamamoto M, Takahashi H, Tabeya T, Suzuki C, Naishiro Y, Ishigami K, et al. Risk of malignancies in IgG4-related disease. Mod Rheumatol 2012 2012-06-01;22(3):414-8.

[3] Takahashi N, Ghazale AH, Smyrk TC, Mandrekar JN, Chari ST. Possible association between IgG4-associated systemic disease with or without autoimmune pancreatitis and non-Hodgkin lymphoma. Pancreas 2009 200907-01;38(5):523-6.

[4] Choe JY, Go H, Jeon YK, Yun JY, Kim YA, Kim HJ, et al. Inflammatory pseudotumor-like follicular dendritic cell sarcoma of the spleen: a report of six cases with increased IgG4-positive plasma cells. Pathol Int 2013 2013-05-01;63(5):245-51.

[5] Koneval T, Applebaum E, Popovic D, Gill L, Sisson G, Wood GW, et al. Demonstration of immunoglobulin in tumor and marginal tissues of squamous cell carcinomas of the head and neck. J Natl Cancer Inst 1977 1977-1001:59(4):1089-97.

Disclosure of Interest: None declared

DOI: 10.1136/annrheumdis-2017-eular.3999

\section{AB1034 SCORING SYSTEMS OF MUSCLE MRI IN IDIOPATHIC INFLAMMATORY MYOPATHIES}

K. Kubinova, H. Mann, J. Vencovsky. Institute of Rheumatology, 1st Faculty of Medicine, Charles University, Prague, Czech Republic

Background: MRI is a widely used radiological method for assessing muscle involvement in idiopathic inflammatory myopathies (IIM). There is still no universally accepted and validated scoring protocol for the quantification of pathological changes in muscles.

Objectives: To identify MRI scoring systems used in previous studies. To summarize the most frequently evaluated MRI features and to suggest parameters for a unified scoring system, that has to be validated in the future.

Methods: A detailed literature search was conducted in the standard medical databases. Information regarding individual MRI scoring systems were obtained from the methodological explanations and their parameters were compared. lymphocytes. Proliferation of fibrous tissue was only seen in one specimen. 14

Results: We identified different scoring systems with a large variability of assessed localizations and parameters (Table 1). Muscle oedema as a sign of active muscle inflammation was evaluated in all studies. There were some studies using modified Mercuri score for evaluation of the fatty infiltration as a marker of chronic muscle damage or the Goutallier grading $(1,2)$, developed originally for the assessment of inherited neuromuscular disorders or structural changes in orthopedics. Perifascicular oedema or soft-tissue oedema were also assessed in some cases. There was no concordance between evaluated muscle groups. Conclusions: MRI plays a significant role in the evaluation of pathological changes in IIM. This search demonstrated, that there is no widely used, standardized method for assessment of a MRI finding. According to our results, a future concept of MRI scoring system should include evaluation of muscle oedema, fatty infiltration and possibly also the presence of perifascicular (-fascial) and subcutaneous tissue inflammation. Muscle groups most convenient for evaluation have to be determined as well.

References:

[1] Goutallier D, et al. Influence of cuff muscle fatty degeneration on anatomic and functional outcomes after simple suture of full-thickness tears. J Shoulder Elbow Surg, 2003;12(6):550-4.

[2] Zheng $Y$, et al. Magnetic resonance imaging changes of thigh muscles in myopathy with antibodies to signal recognition particle. Rheumatology, 2015;54(6):1017-1024.

Acknowledgements: Supported by the project (Ministry of Health, Czech Republic) for conceptual development of research organization 00023728 (Institute of Rheumatology).

Disclosure of Interest: None declared

DOI: 10.1136/annrheumdis-2017-eular.3656

\section{AB1035 EXAMINATION OF ULTRASOUND FINDINGS IN UNDIFFERENTIATED SPONDYLOARTHRITIS PATIENTS WITH DACTYLITIS}

K. Fujikawa ${ }^{1}$, Y. Endo ${ }^{1}$, A. Mizokami ${ }^{1}$, M. Mine ${ }^{2}$, A. Kawakami ${ }^{3}$.

${ }^{1}$ Rheumatology, Japan Community Healthcare Organization, Isahaya General Hospital; ${ }^{2}$ Rheumatology, Suga Orthopedic Hospital, Isahaya; ${ }^{3}$ Immunology and Rheumatology, Graduate School of Biomedical Sciences, Nagasaki University, Nagasaki, Japan

Objectives: To evaluate the ultrasound findings in undifferentiated spondyloarthritis (USpA) patients with or without dactylitis.

Methods: Between April 2014 and December 2016, sixty-six patients with uSpA diagnosed at our center were consecutively enrolled. The diagnosis of uSpA was made by the Japan College of Rheumatology (JCR)-certified rheumatologists and dactylitis was defined as sausage-digit appearance. Ultrasound, clinical and laboratory findings at diagnosis in patients with dactylitis (dactylitis group; $n=30$ ) were compared to those without dactylitis (non-dactylitis group; $n=36$ ). Grey scale (GS) and power Doppler (PD) signals of the wrist and finger joints, PD signal of extensor and flexor tendon sheaths, and PD signals of the collateral ligament of the fingers in both hands were assessed by ultrasound. Ultrasound assessment was made by JCR-registered sonographers.

Results: There were no significant differences in clinical and laboratory findings, including inflammatory back pain, arthritis of the lower limbs, tenderness of the entheses, radiographic/MRI changes of sacroiliac joint and HLA-B27 allele frequency, between two groups. In ultrasound findings, the dactylitis group had significantly more PD signals of the flexor tendon sheaths $(83 \%$ vs. $22 \%$, $p<0.0001)$, the collateral ligament ( $83 \%$ vs. $25 \%, p<0.0001)$, and the MCP joint ( $30 \%$ vs. $3 \%, p<0.01)$ as compared with the non-dactylitis group. In logistic

Figure 1. Logistic regression analysis of ultrasound findings for the contribution of diagnosis of dactylitis
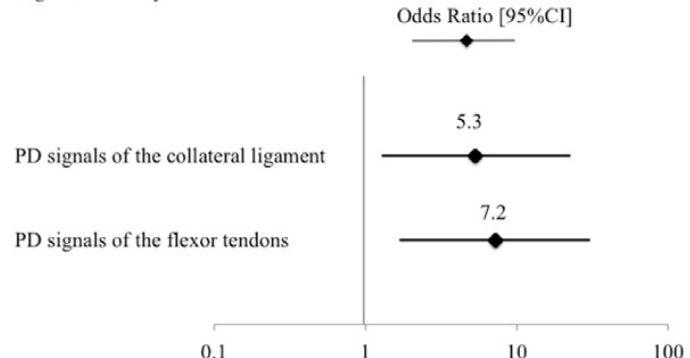

Abstract AB1034 - Table 1. Muscle MRI scoring systems

\begin{tabular}{|c|c|c|c|c|c|}
\hline Author & Muscle oedema & Fatty infiltration & Sequences & Muscle groups & Other aspects \\
\hline Pipitone 2016 & $1=$ present, $0=$ absent & - & STIR & 17 bilat. & - \\
\hline Andersson 2015 & $1=$ present, $0=$ absent & 0 - 4 Goutallier gr. & T1W, STIR & thigh, NS & - \\
\hline Malattia 2014 & $0=$ no abnormalities, $1=$ mild-moderate $<50 \%, 2=$ high degree $>50 \%$ & - & STIR & 42 (whole body MRI) & $\begin{array}{c}\text { perifascicular + subcutaneous } \\
\text { tissue inflammation }\end{array}$ \\
\hline Zheng 2014 & 0-5 scale from normal to moderate intrafascicular global oedema & 0-5 modif. Mercuri score & T1W, STIR & 12 , thigh muscles bilat. & - \\
\hline Davis 2011 & $0=$ absent, $1=$ mild, $2=$ moderate, $3=$ severe & - & STIR & 4 , thigh bilat. & soft-tissue + perifascicular oedema \\
\hline Studynkova 2007 & VAS $0-10$ & - & STIR & thigh muscles, NS & muscle oedema extent + total MRI affection \\
\hline
\end{tabular}

